\title{
DEVELOPMENT OF PREFABRICATED COMPONENTS WITH MINIMIZED CEMENT CONTENT THROUGH THE USE OF FINE-GRAINED SECONDARY MATERIALS
}

\author{
MARCEL JOGL ${ }^{1}$, ŠÁRKA PEŠKOVÁ ${ }^{1}$, RADOSLAV SOVJÁK ${ }^{1}$, JAN VALENTIN $^{2}$ \& ROSTISLAV ŠULC ${ }^{3}$ \\ ${ }^{1}$ Experimental Centre, Faculty of Civil Engineering, Czech Technical University in Prague, Czech Republic \\ ${ }^{2}$ Department of Road Structures, Faculty of Civil Engineering, Czech Technical University in Prague, \\ Czech Republic \\ ${ }^{3}$ Department of Construction Technology, Faculty of Civil Engineering, Czech Technical University in Prague, \\ Czech Republic
}

\begin{abstract}
This paper describes the results and an example of the use of secondary materials in concrete for application to practice, which were obtained from a project in cooperation with the University CTU in Prague and company Hochtief $\mathrm{CZ}$ a.s. Extensive experiments were carried out in the project, where the ideal concrete with admixtures was sought. Prefabricated part made of concrete composite with minimized cement content was realized, which replaced binder based on the use of secondary materials that apply modified energy by-products. It is a hydraulic ternary binder, which replaces cement in the amount of $50 \%$ compared to the original production formulation of concrete. The prefabricated part uses recycled materials or secondary raw materials of the by-product type in combination with the reduction of energy intensity, which is primarily associated with the production of cement. The implementation of the operational test of the production of the basic slab element for the prefabricated part was carried out at the concrete plant of the company Chynovska 714, 39111 Plana nad Luznici of the company Hochtief CZ a.s., on 2 October 2019 with the possibility of further use for soundproof walls waste rubber in a thickness of $20 \mathrm{~mm}$, with resistance to aggressive environments and service life of 30 years. The new implementation has a positive impact on the environment while achieving a lower carbon footprint and at the same time the use of part of materials that otherwise end up as waste, the implementation leads to $\mathrm{CO}_{2}$ reduction and actively supports the Waste Management Plan of the Czech Republic (WMP) for the period 2015-2024.

Keywords: fly ash, hydraulic ternary binder, recycled materials, prefabricated components, mechanical properties.
\end{abstract}

\section{INTRODUCTION}

Environmental issues have motivated extensive research on sustainable alternatives in order to replace materials that require high energy costs in the modern engineering industry. Great attention has been paid to the use of industrial waste in the production of low-cost building materials with desirable mechanical characteristics, such as high strength, modulus of elasticity, and strain capacity.

Production of cement is not only energy intensive but it is also one of the main $\mathrm{CO}_{2}$ emission source in the world. Every tonne of ordinary Portland cement that is produced releases on average a similar amount of $\mathrm{CO}_{2}$ into the atmosphere, or in total roughly $6 \%$ of all manmade carbon emissions. Improved production methods and formulations that reduce or eliminate $\mathrm{CO}_{2}$ emissions from the cement manufacturing process are thus high on the agenda [1].

Therefore there are a lot of attempts to find out environmentally friendly materials with pozzolanic properties to replace either part or the whole cement amount in building structures. Emission reduction is needed to counter the impacts on product cost of new regulations, green taxes and escalating fuel prices. In this regard, locally available minerals, recycled materials and (industry, agriculture and domestic) waste may be suitable for 
blending with cement as a substitute, or in some cases replacement, binders [1], [2]. Modifying concrete with various additives and admixtures is a standard method for improving its properties while utilizing industrial by-products [3]. Furthermore, the concept of reusing by-products builds upon international directives regarding waste reduction and the utilization of by-products, including the Czech Republic's 2015-2024 Waste Management Plan [4]. The Czech government, which approved this plan, additionally supports $\mathrm{CO}_{2}$ reduction in newly designed structures [2].

Fly ash, blast furnace slag, and silica fumes are three well-known examples of cement replacement materials that are in use today [1]. The generation of electric power by combustion of coal and the subsequent desulfurization of flue gases give rise to fly ashes, gypsum and fluidized-bed fly ashes. The volume of these products produced all over the world is huge. Fly ash is formed during the combustion of coal at temperatures exceeding $950^{\circ} \mathrm{C}$ (frequently above $1100^{\circ} \mathrm{C}$ ). The fly ash rejected during the fluidized-bed combustion of coal represents another product. The fluidized-bed combustion of coal in the Czech Republic as well as in some other countries is combined with the flue gas desulfurization by mixing pulverized coal with pulverized limestone. About 1.5 million tons of this FBC fly ash is produced in the Czech Republic annually [5].

\section{EXPERIMENTAL PROGRAM}

The present work aims to verify the functionality of the proposed concrete recipes and their applicability in the form of selected types of prefabricated components made of selfcompacting concrete. Prefabricated components are presented in the form of slab elements and a beam element with a length exceeding $5 \mathrm{~m}$. All components are made with minimized cement content. Cement-based binder is replaced by a hydraulic ternary binder, which is based on the use of secondary materials that use to the maximum extent modified energy byproducts. Used ternary binder replaces cement in the amount of $50 \%$ compared to the original production recipe of self-compacting concrete L42/1

\subsection{Concrete composition}

Reference mixture L42/16, shown in Table 1, is intended for the production of selfcompacting concrete SCC of class C 40/50, X0, XC1-XC4, XD1-XD2, XF1, XA1-XA2, consistency SF2, viscosity VS1 [6], [7]. The alternative mixture SUB-01 is designed with $50 \%$ cement replacement by a ternary binder based on energy by-products $-95 \%$ of fly ash and $5 \%$ of other additives.

\subsection{Description of the production of prefabricated elements}

The first test of operational production of the prefabricated slab element, as well as the beam element, was carried out at the concrete plant Hochtief CZ a.s. in Plana nad Luznici, Czech Republic, on 2 October 2019. Figs 1-3 are presenting in detail the course of the experiment and the production of a functional prefabricated parts. The dimensions $5600 \times 295 \times 600 \mathrm{~mm}$ were intended for the beam element, with the assumption that it will be subsequently tested for deformation characteristics and mechanical sampling for further laboratory tests will be performed.

The slab element had dimensions of $2000 \times 2000 \times 90 \mathrm{~mm}$ and is expected to be adapted to a suitable dimension, which in the follow-up research would serve as a supporting part for the development of noise protection panel using a suitable type of absorber - probably based on rubber. 
Table 1: Mix designs for experimental batches in $\mathrm{kg} / \mathrm{m}^{3}$.

\begin{tabular}{|c|c|c|}
\hline \multirow{2}{*}{ Components } & L42/16 & SUB-01 \\
\hline & $1 \mathrm{~m}^{3}$ & $1 \mathrm{~m}^{3}$ \\
\hline CEM 52.5 R & $386 \mathrm{~kg}$ & $193 \mathrm{~kg}$ \\
\hline Ternary binder & $0 \mathrm{~kg}$ & $193 \mathrm{~kg}$ \\
\hline Limestone carmeuse & $172 \mathrm{~kg}$ & $172 \mathrm{~kg}$ \\
\hline Aggregate $0-4 \mathrm{~mm}$ & $815 \mathrm{~kg}$ & $815 \mathrm{~kg}$ \\
\hline Aggregate $4-8 \mathrm{~mm}$ & $365 \mathrm{~kg}$ & $365 \mathrm{~kg}$ \\
\hline Aggregate $8-16 \mathrm{~mm}$ & $427 \mathrm{~kg}$ & $427 \mathrm{~kg}$ \\
\hline Superplasticizer Stachement 787 & $5.07 \mathrm{~kg}$ & $7.5 \mathrm{~kg}$ \\
\hline Superplasticizer Stabilan $300 \mathrm{~F}$ & $0.51 \mathrm{~kg}$ & $0 \mathrm{~kg}$ \\
\hline Water & 1971 & 1971 \\
\hline Bulk density of fresh mixture & $2368 \mathrm{~kg} / \mathrm{m}^{3}$ & \\
\hline Water-cement ratio w/c & 0.51 & 0.51 \\
\hline Consistency (slump test) $-0 \mathrm{~min}$ & SF2 & $700 \mathrm{~mm} \quad \mathrm{SF} 2$ \\
\hline Viscosity $(\mathrm{t} 50)-0 \mathrm{~min}$ & VS1 & $1.28 \mathrm{~s} \quad \mathrm{VS} 1$ \\
\hline Consistency (slump test) $-5 \mathrm{~min}$ & $720 \mathrm{~mm} \quad \mathrm{SF} 2$ & $660 \mathrm{~mm} \quad \mathrm{SF} 2$ \\
\hline Viscosity $(\mathrm{t} 50)-5 \mathrm{~min}$ & $1.25 \mathrm{~s} \quad \mathrm{VS} 1$ & $1.78 \mathrm{~s} \quad \mathrm{VS} 1$ \\
\hline
\end{tabular}
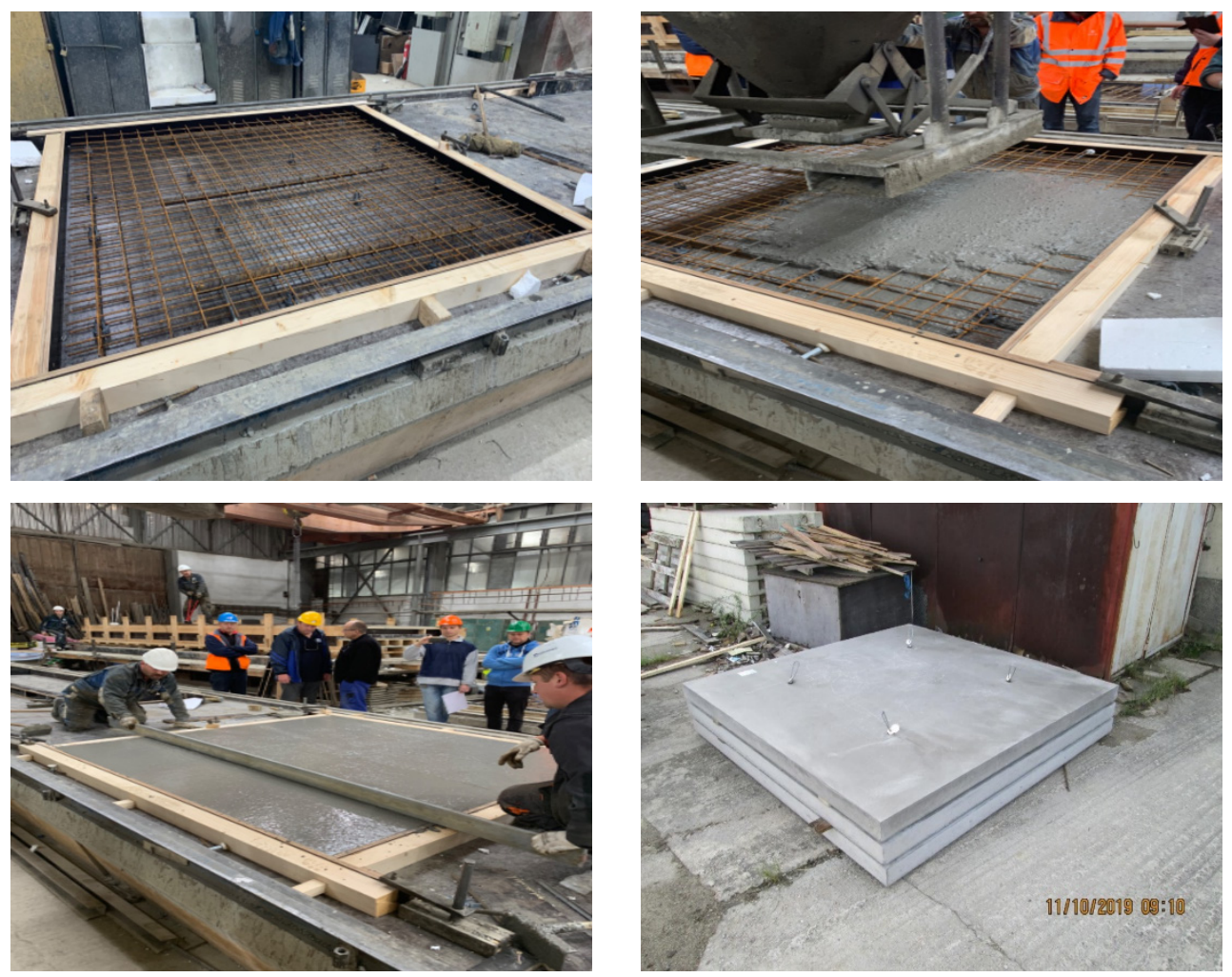

Figure 1: Production of the concrete slab element with 50\% cement substitution. 


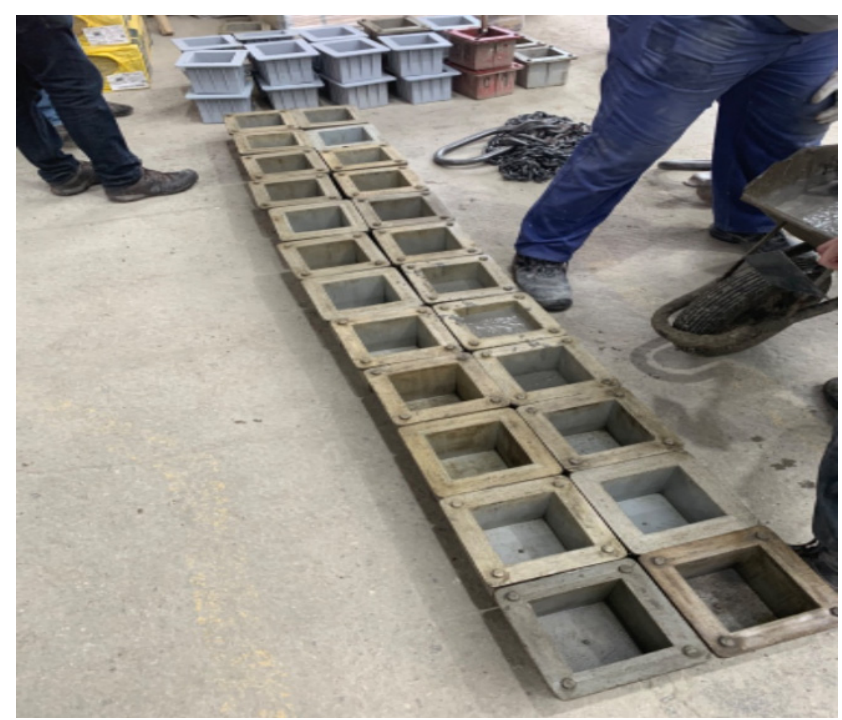

Figure 2: Sampling for mechanical tests of a functional prefabricated parts.
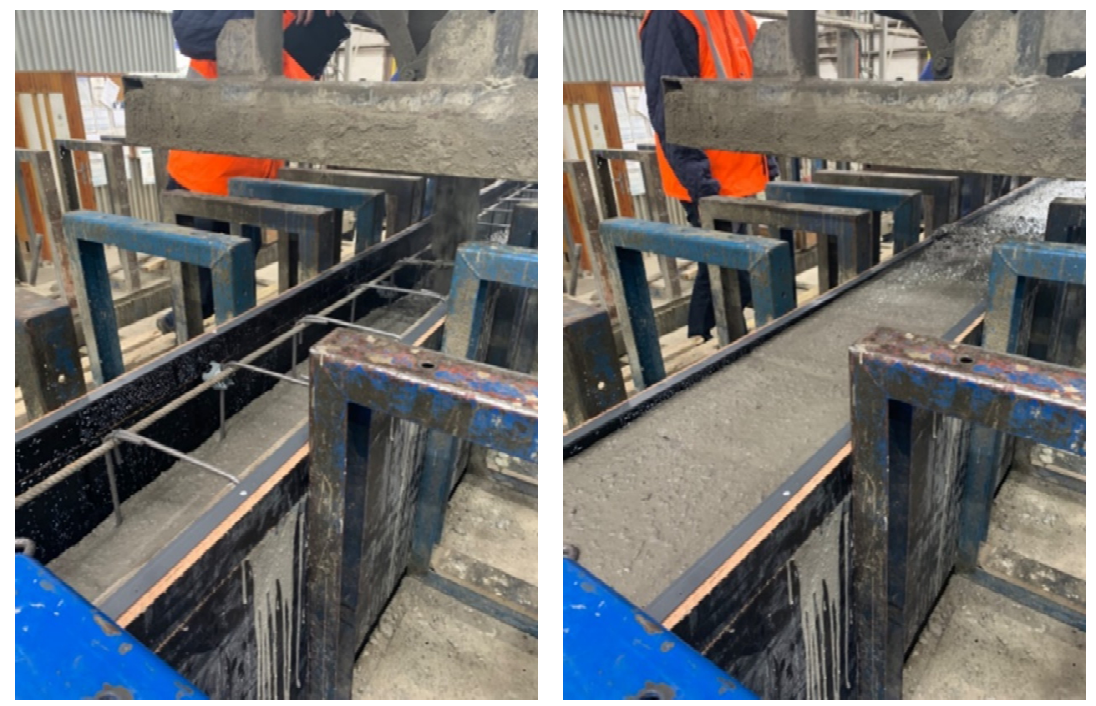

Figure 3: Production of the concrete beam element with 50\% cement substitution.

\subsection{Technical characteristics of the alternative mixture with a new type of ternary binder}

On 2 October 2019, two series of self-compacting concrete were produced according to the production recipe L42/16 and SUB-01. Both series were compared with each other based on the viscosity and consistency of the fresh mixture, and bulk density and compressive strength of matured specimens, see Figs 4-8. All specimens were determined by European standard methods. 
High Performance and Optimum Design of Structures and Materials IV 157

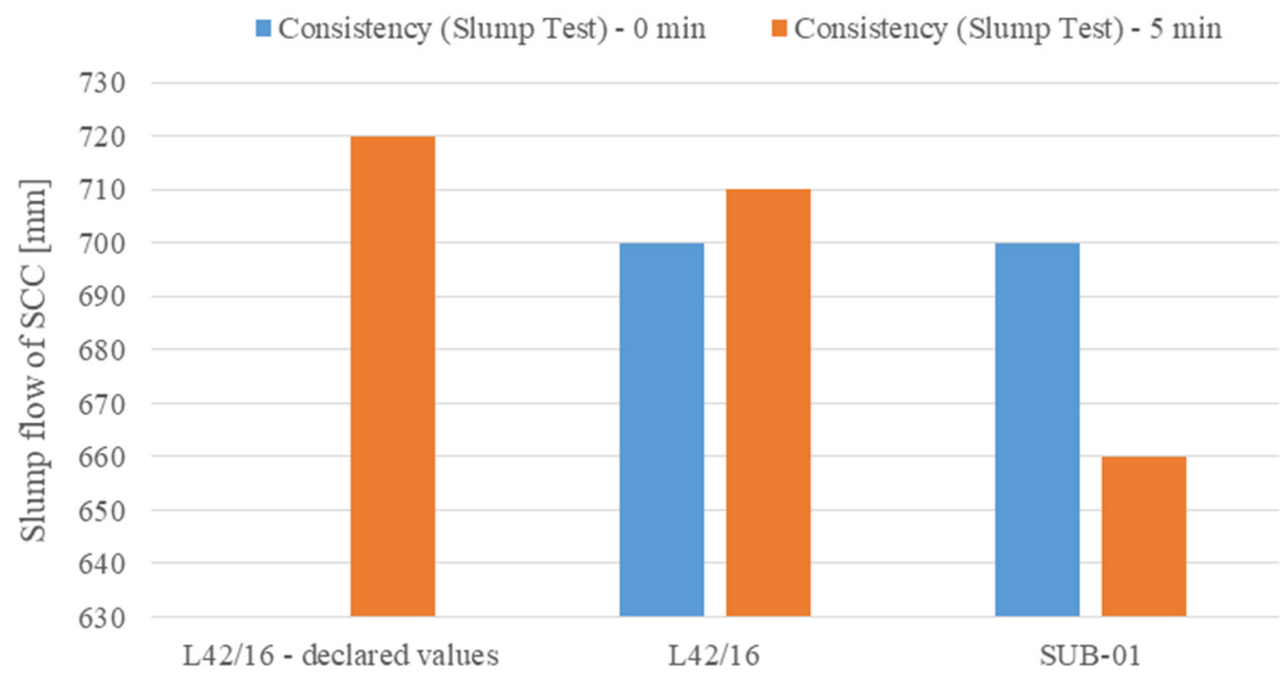

Figure 4: Consistency values of freshly mixed concrete.

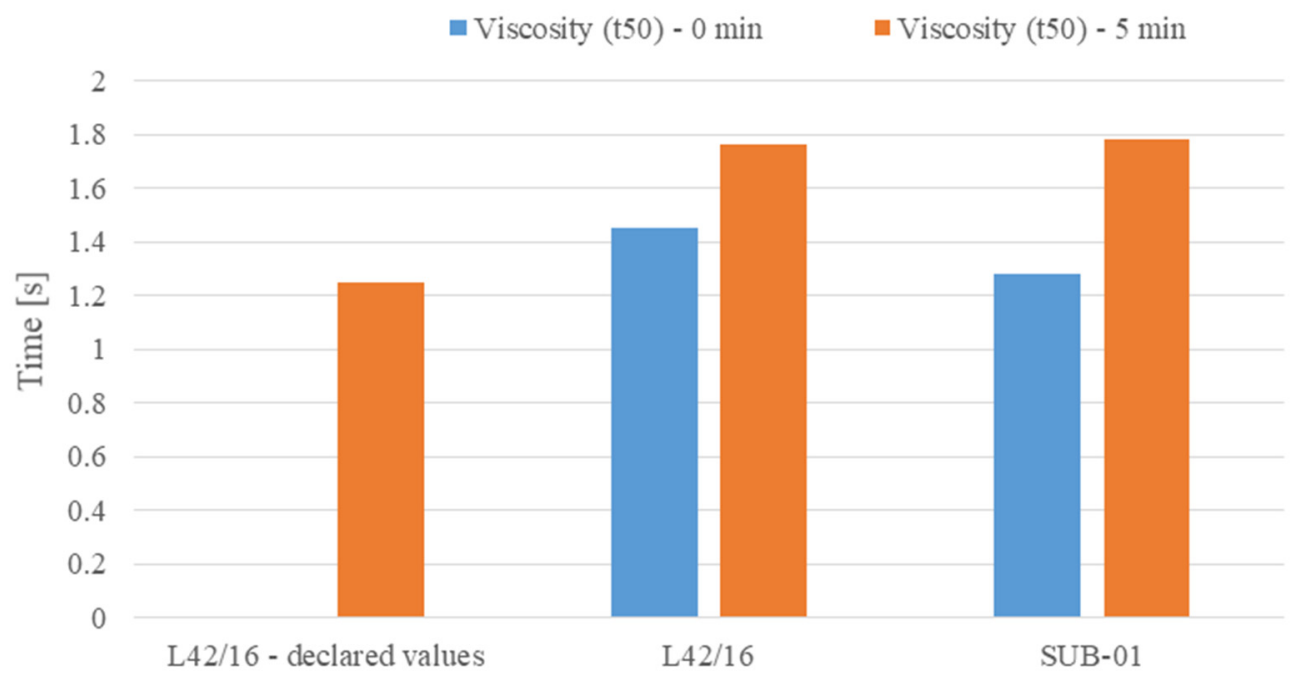

Figure 5: Viscosity results of freshly mixed concrete. 


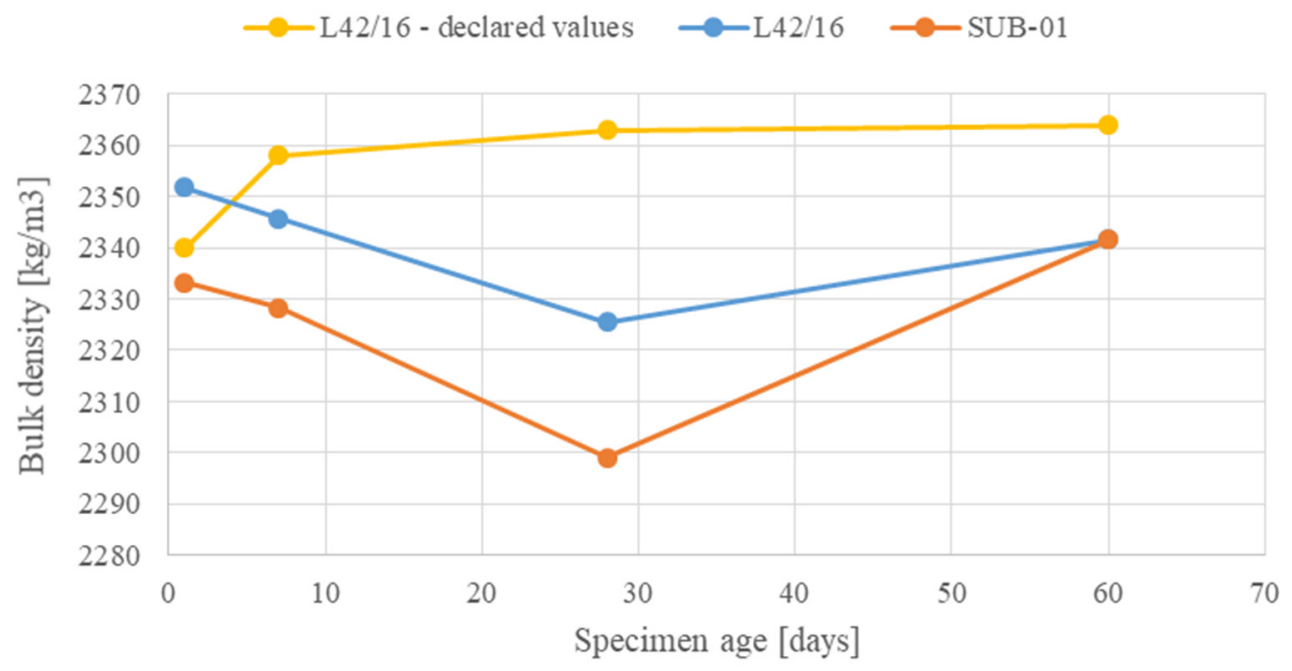

Figure 6: Bulk density values of hardened concrete mixtures.

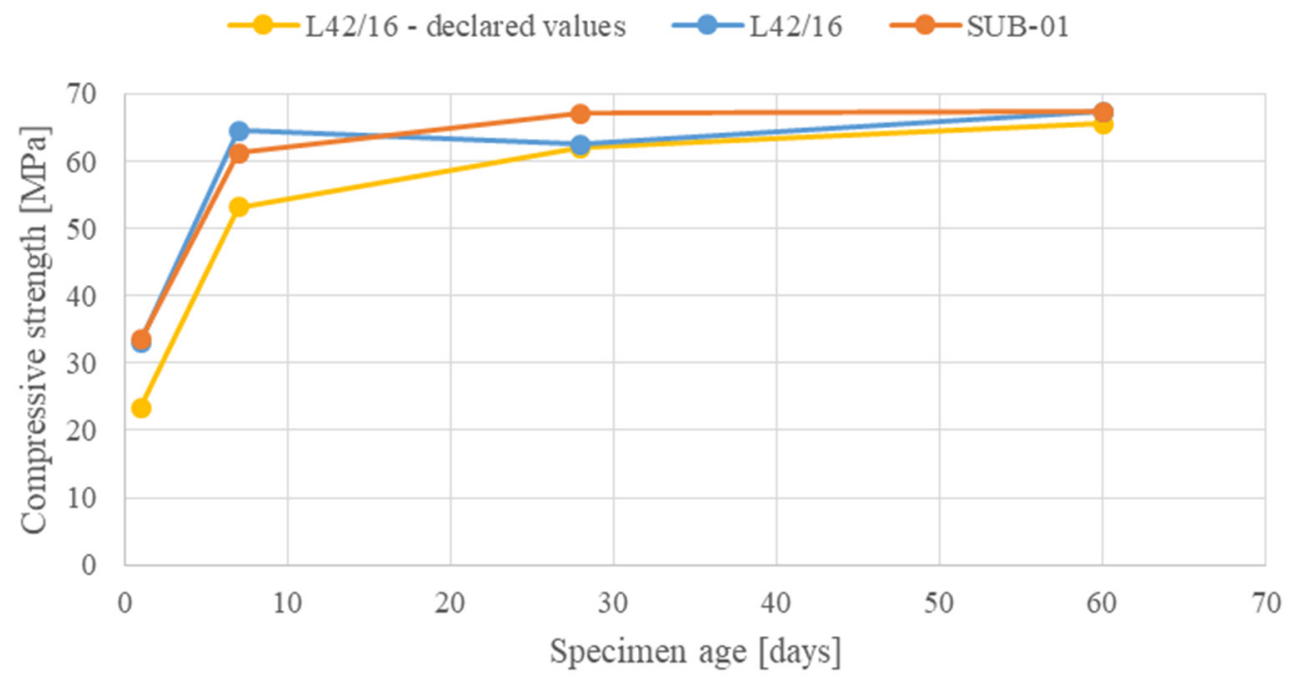

Figure 7: Compressive strength results of test specimens over time. 


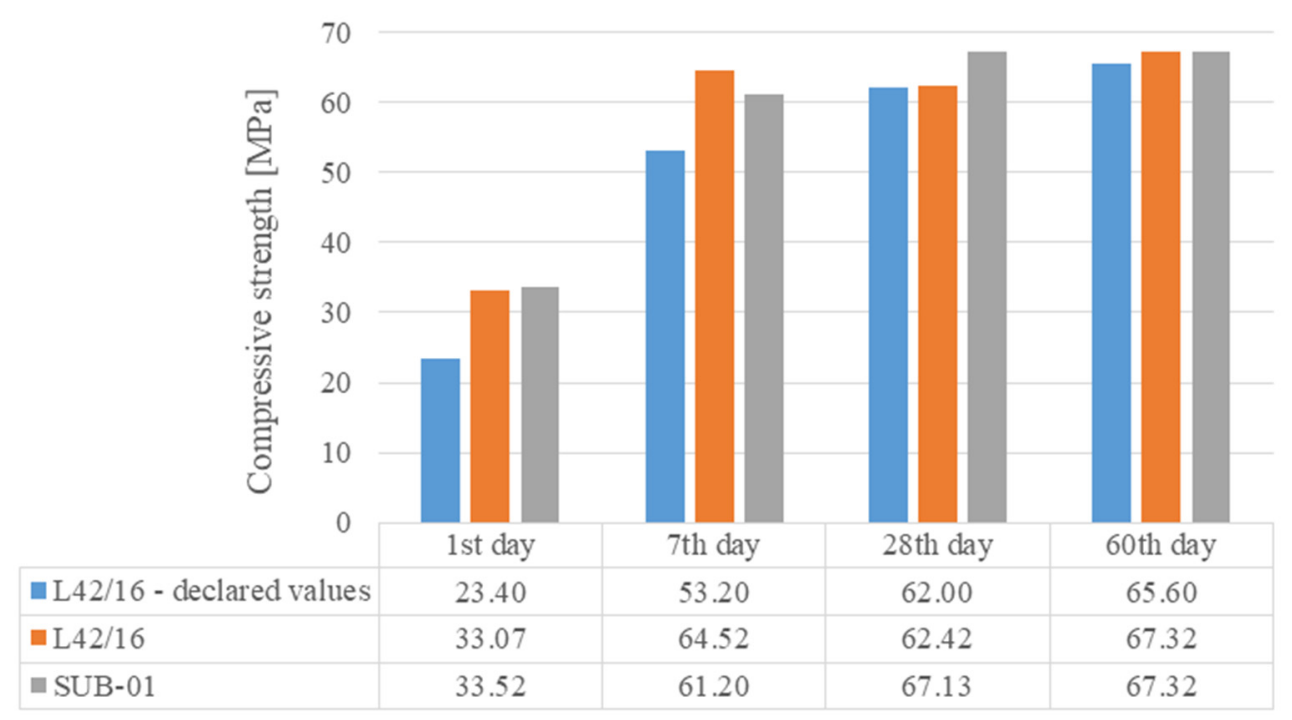

Figure 8: Summary of the compressive strength results of produced test specimens.

It has been discovered that under the given production conditions, the curing time of the SUB-01 series is extended, while comparable values can be expected after approx. 10-14 days, see Figs 7 and 8.

The compressive strength after 28 days is slightly higher in the SUB-01 series. Both produced series did reach the declared strength parameters for SCC L42/16.

\section{CONCLUSION}

This implementation has a positive impact on the environment with the combined achievement of a lower carbon footprint and at the same time the use of some materials that otherwise end up as waste in landfills and thus represents an environmentally potential problem. Furthermore, the experiment leads to a reduction in $\mathrm{CO}_{2}$ and actively supports the Waste Management Plan of the Czech Republic for the period 2015-2024.

The performed primary verifications will be used to achieve a functional sample, which will be based on the proposed recipes and knowledge of pilot production. At the same time, variants, where blast furnace slag (ungranulated) is applied, were tested. This latent hydraulic material has a different behaviour compared to the used ternary binder in our experiment and the assessment of whether it will be usable for prefabrication concretes, especially concerning a slower onset of initial strengths, continues.

\section{ACKNOWLEDGEMENTS}

The experimental activity was supported by the company Hochtief $\mathrm{CZ}$ a.s. and the authors as well gratefully acknowledge the financial support provided by the Technology Agency of the Czech Republic under project No. TN01000056/10: Development of Prefabricated components with minimized cement content through the use of fine-grained secondary materials. 


\section{REFERENCES}

[1] Imbabi, M.S., Carrigan, C. \& McKenna, S., Trends and developments in green cement and concrete technology. International Journal of Sustainable Built Environment, 1, pp. 194-216, 2012.

[2] Sovják, R. et al., Utilization of crumb rubber and FBC-based ternary binder in shotcrete lining. Case Studies in Construction Materials, 11, e00234, 2019.

[3] Záleská, M. et al., Physical and chemical characterization of technogenic pozzolans for the application in blended cements. Construction and Building Materials, 160, pp. 106116, 2018.

[4] POH CR, Waste Management Plan of the Czech Republic for the period 2015-2024, Ministry of the Environment of the Czech Republic, Prague, 2014. www.mzp.cz/ C1257458002F0DC7/cz/plan_odpadoveho_hospodarstvi_aj/\$FILE/OODP-WMP_CZ translation-20151008.pdf. Accessed on: 7 Nov. 2018.

[5] Škvára, F. et al., Czech fluid sulfocalcic ash and fly ash. Ceramics-Silikáty, 60(4), pp. 344-352, 2016.

[6] ČSN EN $206+$ A1, Concrete: Specification, performance, production and conformity.

[7] ČSN P 73 2404, Concrete: Specification, performance, production and conformity Additional information. 